\title{
AC 2007-707: NASA ADMINISTRATOR'S FELLOWSHIP PROGRAM ? A STEM FACULTY FELLOW'S POINT OF VIEW
}

\section{Goang-Shin Liaw, Alabama A\&M University}

Dr. Goang-Shin Liaw is a Professor of Civil Engineering at Alabama A\&M University located in Huntsville, Alabama. He is currently a NASA Administrator's Fellow, Cohort 10. He has served as Chairman of the Department of Civil Engineering for more than sixteen (16) years and as Interim Dean of the School of Engineering and Technology from 1990 to 1992.

Dr. Liaw holds a Bachelor's degree in Engineering Science from Cheng-Kung University (Taiwan, Republic of China), a Master's degree in Environmental Engineering from the Florida Institute of Technology, and a Ph.D. degree in Mechanical Engineering from the University of Alabama in Huntsville.

Dr. Liaw has been heavily involved in Computational Fluid Dynamics (CFD) for many years. He has planned, directed, and executed more than ten research projects at Alabama A\&M University with contract values in excess of two million dollars. He has authored over 50 technical articles, reports, and papers as a result of his research work.

Dr. Liaw's current research interests are to apply nanotechnology in water and air purification systems in the Environmental Control and Life Support System (ECLSS) for the International Space Station and future Lunar Habitat. 


\title{
NASA Administrator's Fellowship Program - A STEM Faculty Fellow's Point of View
}

\begin{abstract}
The NASA Administrator's Fellowship Program (NAFP) is a unique program designed to enhance the professional development of NASA employees and Science, Technology, Engineering, and Mathematics (STEM) faculty at Minority Institutions (MIs). Through exposure to NASA-related research and facilities, STEM faculty can build relationships with key personnel at NASA and gain valuable experience to further their professional research and teaching goals. With this program, it will also increase the capability of MIs to respond to NASA's research, development, and education needs.

As a current STEM faculty fellow, the author intends to outline and share some personal perspectives and experiences about applying the program as well as the program thus far with other STEM faculty at MIs who might be interested in the program. In this paper, the author highlights some of the benefits of the program and discusses how to get as many of the intended outcomes as possible out of the program. The author also includes opinions and suggestions from other fellows.
\end{abstract}

The benefits of NAFP to faculty are manifold, which may include but are not limited to:

- Access to NASA's internal information networks;

- Opportunity to learn about and expand upon knowledge of NASA's technical and scientific needs;

- Opportunity to demonstrate specific capabilities and technologies at MIs;

- Opportunity to team-up with NASA researchers; and

- Enhancement of undergraduate and graduate research at Minority Serving Institutions (MSIs).

In addition, during the tenure of a fellowship, fellows receive a series of professional training courses designed by UNCFSP. Some of the topics covered by the professional training sessions include leadership development, strategic management, institutional advancement, and external relations and STEM policy.

\section{Introduction}

After many years of teaching, research, and administrative experience at Alabama A\&M University, a Minority Serving Institution (MSI), I was fortunate to have the opportunity to apply for the NASA Administrator's Fellowship Program (NAFP). I was even more fortunate to have been selected to become a NAFP fellow of Cohort 10. With the fellowship, I will be able to stay in a NASA Center, the Marshall Space Flight Center, for twelve (12) months to conduct research, expand my knowledge on current and future technical and scientific endeavors, and have many opportunities to interact and discuss these developments with other scientists and 
engineers. In this paper, I hope to share some personal opinions about and experiences with the program thus far, as well as highlight some of the professional benefits of the program.

This program is currently administered by the United Negro College Fund Special Programs (UNCFSP) through a contract with NASA / Office of Education. More detailed information regarding the NAFP program as well as application procedures and forms can be found on the UNCFSP website at http://www.uncfsp.org.

Typically, applicants to the program fall under one of two categories: NASA Career Employees and STEM Faculty of Minority Serving Institutions. Applicants who are already NASA employees will teach and / or conduct research at a MSI and then participate in a professional developmental assignment at a NASA or NASA related agency, other government agency, or in the private sector. Those who fall under the STEM Faculty category are those who currently work in academia who will conduct research at a NASA or NASA related agency, other government agencies, or in the private sector and then continue NASA-related research at their home institution. Members of both categories will help foster the exchange of technological and scientific research and developments between NASA and Minority Serving Institutions.

\section{Benefits of the STEM Faculty Fellowship Program}

The program provides many mutual benefits to the fellows, the Minority Serving Institutions, and NASA. Not only will a fellow's participation increase the MSI's capability to respond to NASA's research, development, and education needs, but it will also attract more underrepresented STEM minority students to pursue their careers at NASA. In the following paragraphs, I will highlight some of the foremost benefits.

\section{Research Opportunity}

The fellowship program provides the STEM faculty member the opportunity to conduct research at a NASA installation of his or her choice, preferably at one that matches closest to his or her research interests. Through exposure to NASA-related research facilities for twelve (12) months, the STEM faculty member can gain valuable knowledge and experience to further their own research and teaching goals as well as build relationships with other researchers and scientists at NASA.

\section{Financial Support}

Financially, the fellow will remain on the payroll of the home institution. The fellowship will provide the home institution with the fellow's current salary and benefits for the duration of the fellowship spent at a NASA Center. Fellows may receive an additional 55\% of the host site per diem rate if it is necessary to relocate for participation in the fellowship. The fellowship will also provide assistance for relocation expenses as outlined by the NAFP Handbook of Policies and Procedures.

Professional Development Training 
Through the tenure of the fellowship program, fellows have the opportunity to receive a series of professional development training sessions designed by the Institute of Advancement of the UNCF Special Programs Corporation to strengthen the fellow's capabilities in research and the academic preparation of future scientists and engineers. For example, the scheduled training sessions for 2006-07 are: Leadership Development, Strategic Management, Institutional Advancement, External Relations and STEM Policy, and more. In addition, fellows are encouraged to attend professional symposiums, conferences, and other meetings to present papers and obtain up-to-date information on scientific findings and technological breakthroughs. Travel required to attend the gatherings are provided by the program.

\section{NAFP Research Award}

At the end of a successful fellowship experience, faculty fellows are eligible to conduct NASArelated research at their home institution by submitting a proposal for a NAFP Research Award. This award to the fellow's home institution would provide support for the faculty fellow to continue his or her NASA-related research for an additional nine (9) months. In a personal side note, I believe it would be more beneficial to the faculty fellows if the fellowship program could be extended three (3) more months through the summer for a total of twelve (12) months, since most faculty fellows have more free time to conduct research during the summer.

\section{Some Advice / Suggestions to Potential STEM Faculty Fellows}

In the following line items, I would like to share some advice and suggestions to my fellow colleagues who might be interested in this program and have the potential to become NAFP fellows.

- Be prepared. Browse the UNCFSP website (http://www.uncfsp.org) and look-up the NASA Administrator's Fellowship Program (NAFP) under the Division of Science and Technology.

- Download and carefully read the "Instructions and Application Form" from http://www.uncfsp.org/divstNAFPinst.aspx.

- Draft a white paper or research proposal that describes your proposed research activities.

- Contact your research counterpart at a NASA Center who could endorse your research proposal for your NAFP application. If you do not have one, take the initiative to research the various NASA Centers and create a relationship.

- Revise and finalize your white paper or research proposal with your point of contact at NASA.

- Request permission to apply and present your proposal to your University President, School Dean, and / or Department Chair, and make sure to request two endorsement letters from them ahead of time. 
- Follow the NAFP application instructions carefully to prepare your application and forms.

- Obtain two letters of reference that will speak to the quality, fitness, and feasibility of the project. Referees should have knowledge of your qualifications and the proposed project.

- Seek an endorsement from a person within NASA who is in a managerial / supervisory position such as a Director, Branch / Directorate Head, Project Manager, Group Lead, et cetera.

- Submit your application package before the deadline. It usually falls in the month of January.

- Once you have been awarded the fellowship, notify the NAFP Office regarding your decision. When you decide to accept the offer, notify your university administrators and point of contact at NASA immediately, so that they may have enough time to make arrangements for your leave and reception, respectively.

- Attend the important Orientation Symposium to meet with NAFP and NASA Officers and other fellows. You will be given a laptop computer on loan for two years at this time.

- Be patient! Before your start date, contact Academic Affairs personnel at the NASA Center to begin paperwork to apply for a NASA badge. A regular badge can take several weeks to process.

- Arrange an appointment to meet with your NASA monitor as he or she will probably be very busy with day-to-day meetings and activities.

- You will be assigned a user account for access to a computer and the network. Computer acquisition and account assignment may take some time. Again, be patient!

- Be proactive! It is very important to get acquainted with the people around you, including their specialty. If you need help or have questions, make sure to ask!

- Establish your Professional Development Plan (PDP) with your monitor and Department Chair and submit a signed copy to the NAFP Office. This document is required by the NAFP Office and should be revisited frequently.

- Attend group, branch, and other relevant meetings so that you may gather relevant information from all levels and exchange ideas as well as report progress or problems.

- Visit laboratories and other facilities if possible in order to better understand the Center's capabilities and observe new developments. 
- Attend all professional development training sessions sponsored by the UNCFSP Institute for Advancement (SPIA) to enhance your leadership and management skills.

- Understand the organizational structure and become familiar with the system. Get involved with the NASA scientists and engineers in existing research activities as it may lead to new research and help you establish your research project later on.

- Be candid. The working environment at the various NASA Centers may be different from that of academia and the employees may see things differently. However, being open and sincere will help all involved reach a mutual respect and lead to a successful fellowship.

\section{Conclusions}

Based on statistics published by the NAFP Directory of Fellows, since 1997, eighty-one (81) fellows have participated in the program, which includes forty-six (46) NASA employees and thirty-five (35) STEM faculty members. Participation has not yet reached the maximum capacity of the program, especially with respect to STEM faculty. However, the program has received increasing support from NASA employees and STEM faculty.

There is a slogan from the NAFP family: "Once a fellow, always a fellow!" I encourage my fellow colleagues who are looking into this excellent program to take action soon. I hope that the advice and suggestions I have provided will help in making the decision to apply for the fellowship as well as promote a successful fellowship when it is awarded. NAFP needs more quality STEM faculty to support the program.

\section{Acknowledgements}

I would like to thank the NASA Administrator's Fellowship Program Office and NASA for providing me the opportunity to write this paper, as well as my colleagues, Dr. Benjamin G. Penn (Cohort 6, Marshall Space Flight Center) and Dr. M. D. Aggarwal (Cohort 10, Alabama A\&M University), who gave me their candid opinions and suggestions. 